\title{
Analysis of the Drive Shaft Fracture of the Conveyor Belt for Transport of Coal
}

\author{
Mile SAVKOVIĆ, Milan DEDIĆ, Goran PAVLOVIĆ, Miodrag ARSIĆ, Zoran STAMENIĆ
}

\begin{abstract}
The conveyor belt for slag and coal transport in the open mine pit "Kolubara" - Serbia is driven by means of two drive drums, attached on separate shafts. Each shaft is driven by two electric motors on both sides. During exploitation, the conveyor belt drive shafts are subjected to torques and transverse forces due to belt tension. The gearboxes and the bearing units on both sides of the drive drum support each shaft. A fracture of one of the drive shafts of the conveyor belt occurred at its connection point with the gearbox. The first part of the paper defines the loads relevant for shaft calculation, based on measurements in different phases of operation and the manufacturer's data. It is followed by the FEM analysis and fatigue analysis, for the most unfavourable load case. It has been established that the critical stress value has occurred near the connection point between the shaft and the gearbox, in the fracture zone. The second part of the paper presents chemical composition and mechanical properties of material, as well as metallographic examination of fracture surface. The experimental test procedure shows that the fracture has occurred not because of an error in the material but as a consequence of the inadequate heat treatment. Superposition of two negative influences: material fatigue and inadequate heat treatment, expressed in the cross section at the point of fracture is the main case of the conveyor belt shaft fracture.
\end{abstract}

Keywords: conveyor belt; drive shaft of the conveyor belt; experimental testing; fracture analysis

\section{INTRODUCTION}

Transport of excavated material and coal mining in open pit mines represents the most important and most complex process in the technology of surface mining. The length of this transport varies depending on the distance between the pit and the place where material is deposited. In the open pit mine "Kolubara", the length of transport is between $5 \mathrm{~km}$ and $20 \mathrm{~km}$. The capacity of machines performing excavation and depositing, the productivity of excavation and costs of production of ore body depend, to the largest extent, on the organization of this transport.

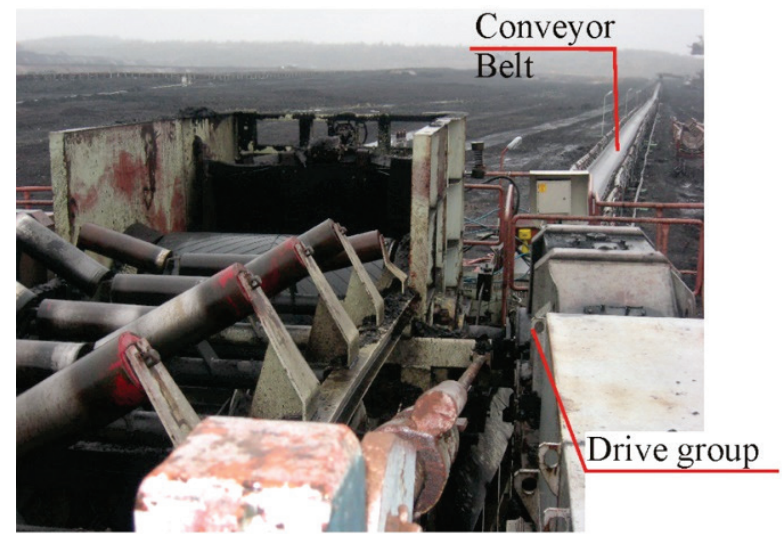

Figure 1 Conveyor belt TS305-drive group

The conveyor belt TS305 (Fig. 1) is used for transport and depositing of slag and coal, and represents one of the most important elements in the chain of transporting excavated material. This conveyor belt is installed as the first in a line, to transfer material from the bucket wheel excavator to the mobile conveyor belt. Its theoretical capacity is $15 \mathrm{t} / \mathrm{h}$, length is $1500 \mathrm{~m}$, and working width is $1500 \mathrm{~mm}$ (Fig. 2).

The drive of this conveyor belt is accomplished by means of two drive drums. Each drive drum is driven by two electric motors, each with the power of $315 \mathrm{~kW}$, through clutches and gearboxes (Fig. 3). The drive is accomplished in such a manner that there is simultaneous starting of both drive drums with gradual start-up in four phases, so that the maximum torque on the shafts of the drive drums is achieved in $30 \mathrm{~s}$ from the moment of starting. Such drive is characteristic for conveyor belts with large capacities and lengths of transport [1-4]. The largest diameter of drive drum shaft is $170 \mathrm{~mm}$, located at the support, i.e. $380 \mathrm{~mm}$ at the point of connection with the drive drum (Fig. 4). The shaft length is $4800 \mathrm{~mm}$, its mass $2794 \mathrm{~kg}$, and rotation frequency $61.25 \mathrm{~min}^{-1}$. The shaft is by one of its ends inserted into the gearbox and connected with it through stiffening rings, by means of which it receives its drive.

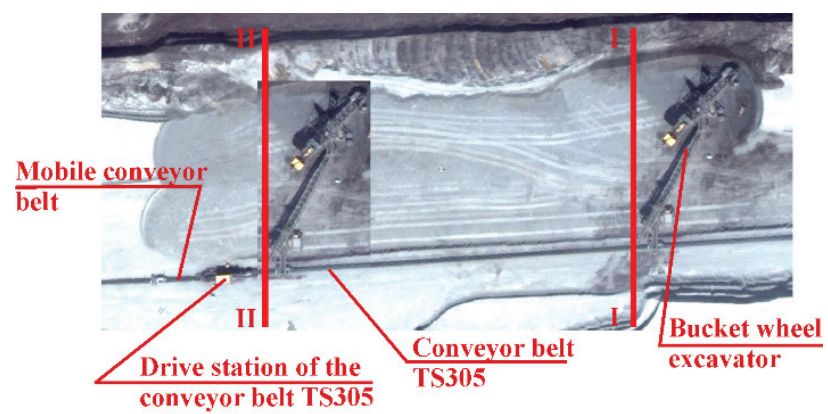

Figure 2 Position of the conveyor belt within the transport

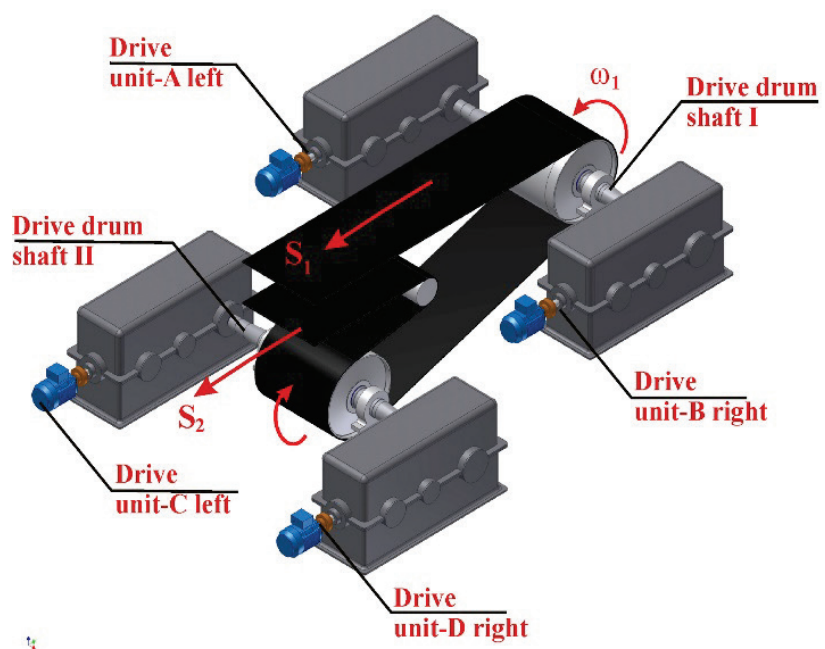

Figure 3 Scheme of power supply of the drive drums of the conveyor belt TS305 


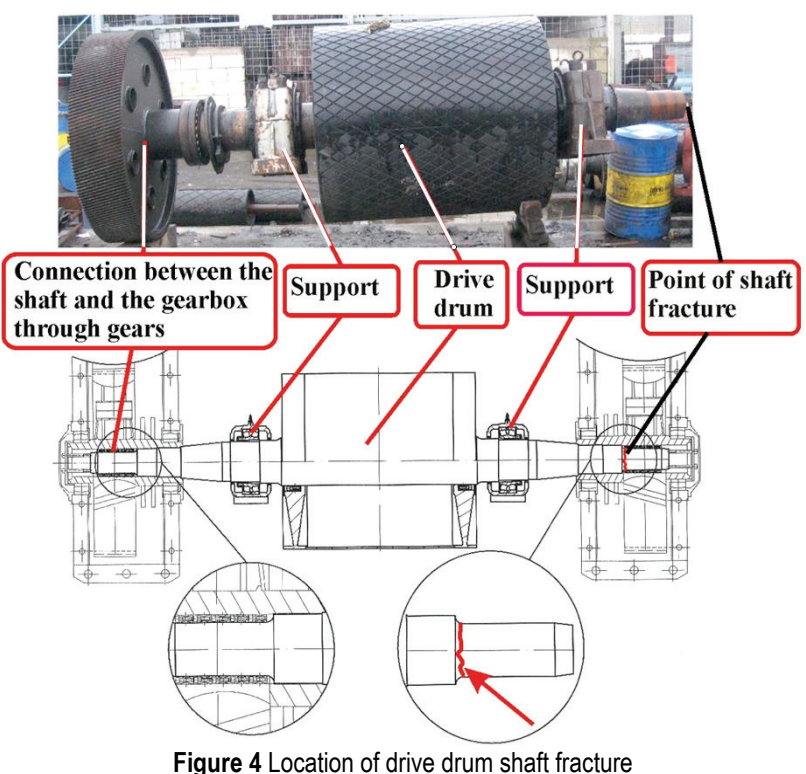

\section{CAUSE OF DRIVE SHAFT FRACTURE}

Investigation of causes of damage of the drive drum shaft of the conveyor belt TS305 was performed in two phases:

- stress state analysis, and

- testing of material, including fracture surface.

\subsection{Calculation of Stresses}

Loading of the drive drum shaft of the conveyor belt TS305 depends on its service conditions. The largest loads of the conveyor belt shaft appear while starting the loaded conveyor belt when the bucket wheel excavator is near the return point (position I-I, Fig. 2). In that case, there is the largest quantity of material that is being transported on the conveyor belt. A more favourable case of conveyor belt operation is in the usual mode of operation, which starts approximately $30 \mathrm{~s}$ after starting the drive, while the bucket wheel excavator is near the conveyor belt drive (position II -II, Fig. 2). In this mode loads are up to 2.5 times smaller. During exploitations in pits, the conveyor belt is moved following the position of the bucket wheel excavator and spreader, so that it may enter the zone with terrain inclination which additionally makes its operation difficult. Torque loads recordings are presented in Fig. 6 for different service conditions. Additional loads are considered in [5, 6], but not here, since it was assumed that shaft was made in accordance with its design. Load changes are determined more precise by means of electric current measurements during operation, which is a common method in practice, [7].
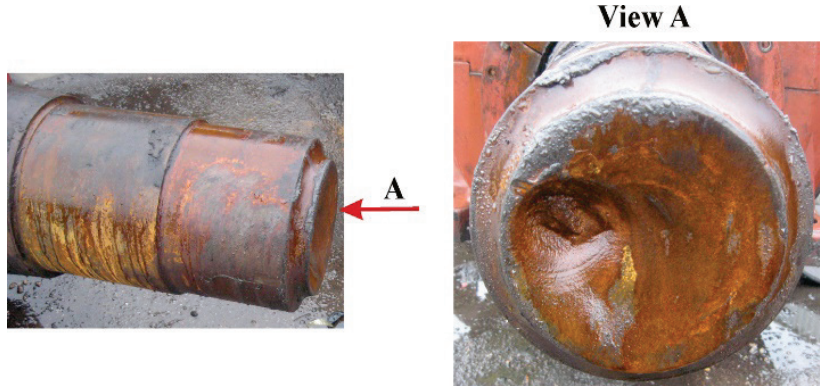

Figure 5 Fracture surface of drive drum shaft of the conveyor belt TS305

The stress state analysis of drive shaft was performed by using the finite element method (FEM). In accordance with its design, the shaft support was accomplished through bearings at points $\mathrm{C}$ and $\mathrm{D}$ (Fig. 7). The shaft is also supported at points $\mathrm{A}$ and $\mathrm{B}$, i.e. through stiffening rings $\mathrm{A}$ and $\mathrm{B}$, but it also receives its drive in the form of torque. At the support $\mathrm{C}$, the shaft transmits the torque through the stiffening rings to the drum (Fig. 4 and Fig. 7).
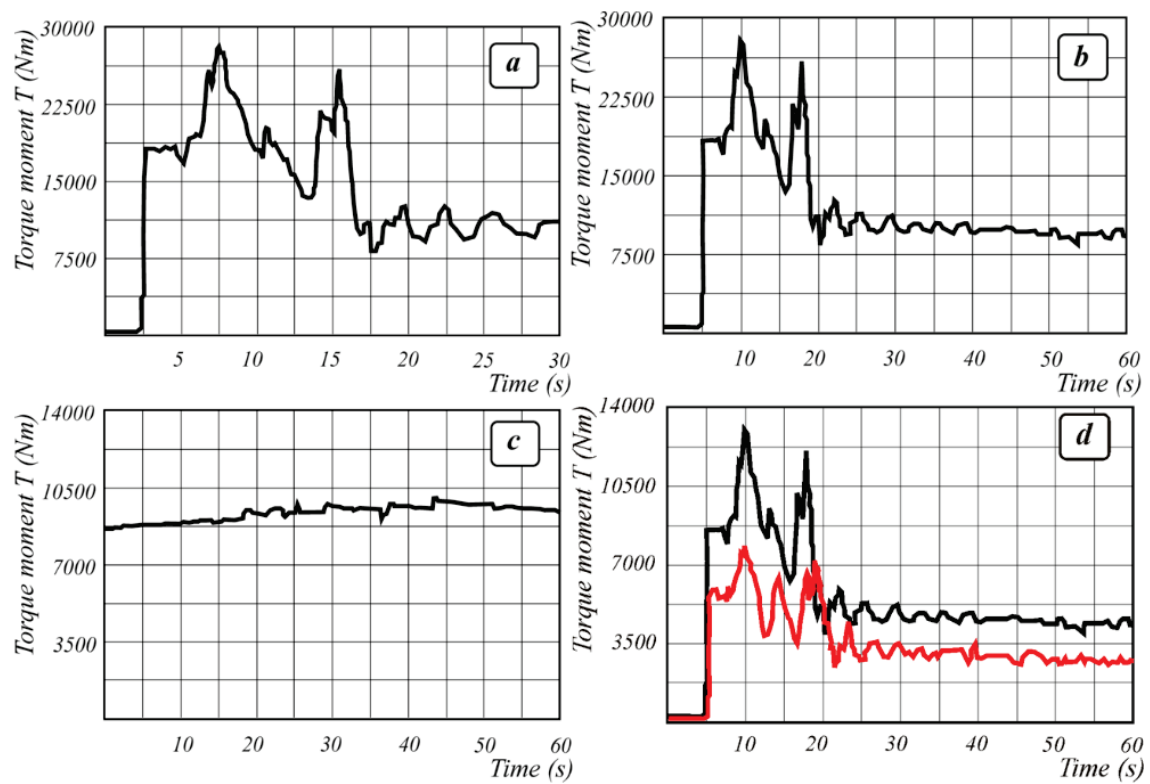

Figure 6 Torque loading of drive drum shaft: (a) starting full conveyor belt - excavator and spreader near the return point, measurement time $30 \mathrm{~s}$; (b) starting the full conveyor belt - excavator and the spreader near the return point, measurement time $60 \mathrm{~s}$; (c) loading of shaft in the nominal (stationary) mode of operation - excavator and the spreader near the return point; (d) comparative presentation of two measurements of starting the conveyor belt - the excavator and the spreader near the conveyor belt drive 


\begin{tabular}{|c|c|}
\hline Support & $\mathrm{A}$ \\
\hline \multicolumn{2}{|l|}{ Definition } \\
\hline Type & \begin{tabular}{|l} 
Fixed Support \\
\end{tabular} \\
\hline \begin{tabular}{|l|} 
Radial \\
\end{tabular} & Fixed \\
\hline Axial & Fixed \\
\hline \begin{tabular}{|l|} 
Tangential \\
\end{tabular} & Fixed \\
\hline Suppressed & No \\
\hline Support & B \\
\hline \multicolumn{2}{|l|}{\begin{tabular}{|l|} 
Definition \\
\end{tabular}} \\
\hline Type & \begin{tabular}{|l} 
Fixed Support \\
\end{tabular} \\
\hline \begin{tabular}{|l|l} 
Radial \\
\end{tabular} & Fixed \\
\hline Axial & Fixed \\
\hline \begin{tabular}{|l|} 
Tangential \\
\end{tabular} & Fixed \\
\hline Suppressed & No \\
\hline \begin{tabular}{|l|} 
Support \\
\end{tabular} & $\mathrm{C}$ \\
\hline \multicolumn{2}{|l|}{ Definition } \\
\hline Type & \begin{tabular}{|l} 
Cilindrical Support \\
\end{tabular} \\
\hline \begin{tabular}{|l|} 
Radial \\
\end{tabular} & Fixed \\
\hline Axial & Fixed \\
\hline \begin{tabular}{|l} 
Tangential \\
\end{tabular} & Free \\
\hline Suppressed & No \\
\hline \begin{tabular}{|l|} 
Support \\
\end{tabular} & $\mathrm{D}$ \\
\hline \multicolumn{2}{|l|}{ Definition } \\
\hline Type & \begin{tabular}{|l} 
Cilindrical Support \\
\end{tabular} \\
\hline \begin{tabular}{|l|} 
Radial \\
\end{tabular} & Fixed \\
\hline Axial & Fixed \\
\hline \begin{tabular}{|l} 
Tangential \\
\end{tabular} & Free \\
\hline \begin{tabular}{|l} 
Suppressed \\
\end{tabular} & Free \\
\hline
\end{tabular}

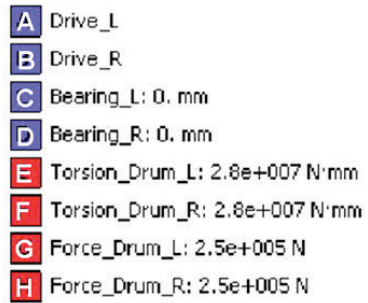

Figure 7 Model of drive drum shaft of the conveyor belt TS305 with support zones (A, B, C and D) and load transmission (E, F, G and H)

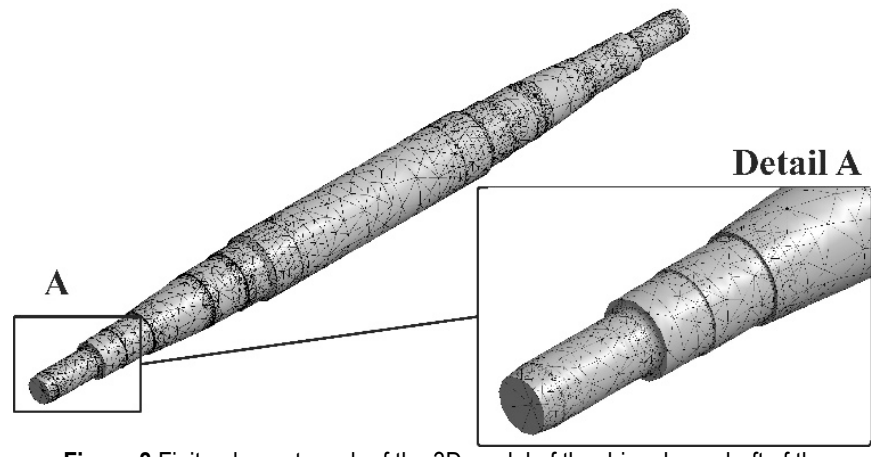

Figure 8 Finite element mesh of the 3D model of the drive drum shaft of the conveyor belt TS305

The FEM 3D model of the drive drum shaft of the conveyor belt BCS was formed by assembling its parts (Fig. 8). The 10-node tetrahedral elements [8] were used to form the FEM model with 49031 nodes and 27850 elements. There are four modes of operation of the conveyor belt characteristic for the calculation [8-9]: conveyor no-load, light-load, average load and maximal load, all of them both for start-up and service condition.

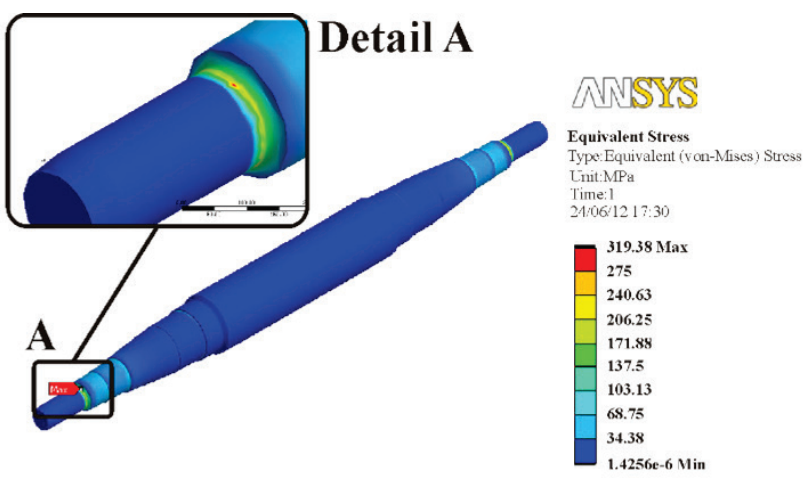

Figure 9 Distribution of the uniaxial stress for load case I

In accordance with [9], the analysis of the drive drum shaft was performed for two load cases [10]:

- loading of shaft in the nominal (stationary) mode of operation - the excavator and the spreader between the drive station and the return point: $\mathrm{T} 1 \mathrm{z}, \max =28 \mathrm{kNm}$ and $\mathrm{H} 1 \mathrm{max}=250 \mathrm{kN}$ - load case $\mathrm{I}$.

- start-up of the full conveyor belt-excavator and the spreader near the return point: $\mathrm{T} 2 \mathrm{z}, \mathrm{max}=64.1 \mathrm{kNm}$ and $\mathrm{H} 2 \mathrm{max}=250 \mathrm{kN}$ - load case II.

Uniaxial stress fields for load cases I and II, are shown in Figs. 9 and 10, respectively, obtained according to the Huber-Hencky-von Mises hypothesis [8, 11-12].

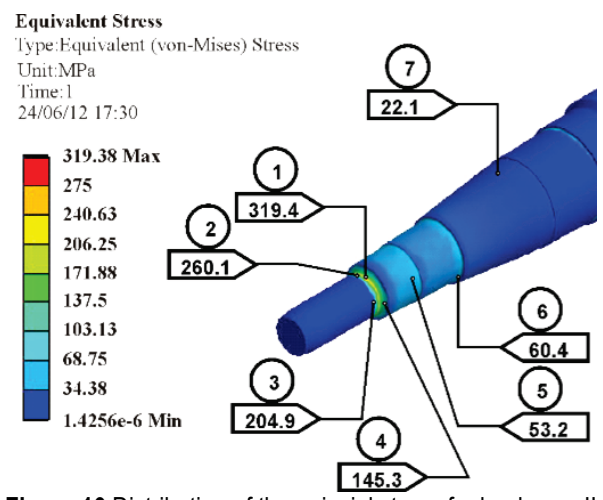

Figure 10 Distribution of the uniaxial stress for load case II

\subsubsection{Fatigue Analysis}

Service stresses obtained by the FEM are presented in Tab. 1. According to the technical documentation of manufacturers, material of shaft is $42 \mathrm{CrMo} 4$ (DIN EN 10083). Fatigue analysis at the point of fracture is performed by using the Goodman endurance diagram. The minimum recommended value of amplitude stress is $\sigma_{a}=$ $330 \mathrm{MPa}$, [13-15]. For real exploitation conditions, in compliance with the recommendations [14-21], the corrected minimum values of amplitude stress $\left(\sigma_{a, m}=125\right.$ $\mathrm{MPa})$ were adopted, while the minimum tensile strength was $\sigma_{m, m}=830 \mathrm{MPa}$, Tab. 2. These values are marked with points $\mathrm{B}$ and $\mathrm{C}$ (Fig. 11), defining the modified boundary of the Goodman diagram. 


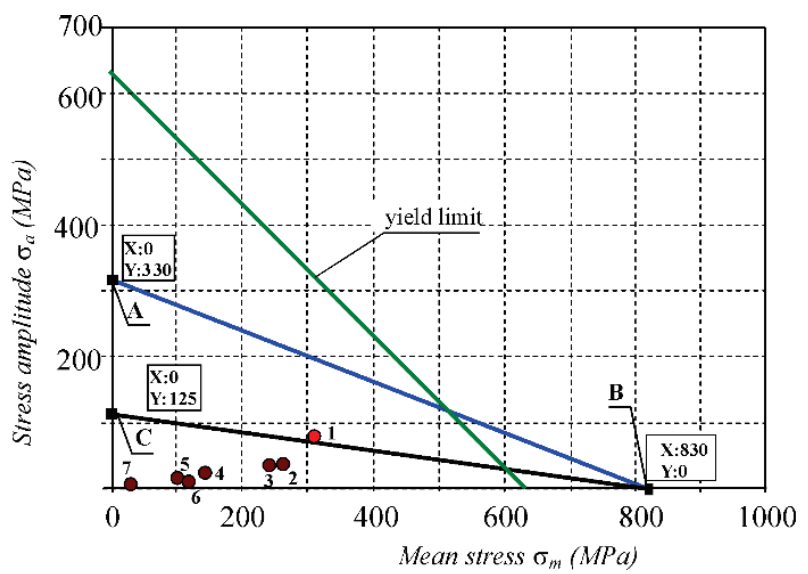

Figure 11 Main and modified Goodman diagrams

Table 1 Values of stresses at the corresponding points established by the finite element method

\begin{tabular}{|l|c|c|c|c|c|c|c|}
\hline $\begin{array}{c}\text { Measuring } \\
\text { point }\end{array}$ & 1 & 2 & 3 & 4 & 5 & 6 & 7 \\
\hline$\sigma_{i, \max }(\mathrm{MPa})$ & 319.4 & 260.5 & 240.6 & 145.3 & 53.2 & 60.4 & 22.1 \\
\hline$\sigma_{i, \min }(\mathrm{MPa})$ & 149.2 & 175.5 & 162.0 & 80.1 & 12.4 & 42.0 & 17.5 \\
\hline$\sigma_{\text {mean }}(\mathrm{MPa})$ & 234.3 & 218.0 & 201.3 & 112.7 & 32.8 & 51.2 & 19.8 \\
\hline$\sigma_{a}(\mathrm{MPa})$ & 85.1 & 42.5 & 39.3 & 32.6 & 20.4 & 9.2 & 2.3 \\
\hline
\end{tabular}

Table 2 Results of examination of mechanical properties of the shaft

\begin{tabular}{|c|c|c|c|c|c|}
\hline \multicolumn{2}{|c|}{$\begin{array}{c}\text { Shaft material 42CrMo4 } \\
\text { (DIN EN 10083) }\end{array}$} & $\begin{array}{c}R_{\mathrm{p} 0,2} \\
(\mathrm{MPa})\end{array}$ & $\begin{array}{c}R_{\mathrm{m}} \\
(\mathrm{MPa})\end{array}$ & $A_{5}(\%)$ & $\mathrm{HV}$ \\
\hline \multirow{2}{*}{ Prescribed values } & from & $\min$ & 750 & $\min$ & 235 \\
\cline { 2 - 6 } & to & 500 & 900 & 13 & 295 \\
\hline \multicolumn{2}{|l}{ Values obtained by testing } & 625 & 830 & 15 & $240-270$ \\
\hline
\end{tabular}

Points for testing the shaft are marked 1 to 7 in Fig. 10. Corresponding stresses (Tab. 1), obtained by the FEM, are below the line A-B, but above the line B-C, i.e. above the modified fatigue line of fatigue, indicating that fatigue safety was not assured.

\subsection{Discussion of FEM Results}

Based on the FEM results, one can conclude that:

- The stress state for case II is less favourable than case I and it covers the situations when the full conveyor belt is started, and the excavator and the spreader are near the return point.

- The level of the stress state in the zone of fracture of the drive shaft for loads II is very high. The values of uniaxial stresses, near the support "B" are 2.4 times higher than the stresses for load case I;

- The safety factor of the drive shaft in the characteristic section for load case I is:

$$
\begin{aligned}
& S=\frac{\sigma_{y}}{\sigma_{e q, \max , I}}=\frac{625}{135.2}=4.6, \text { and for case II: } \\
& S=\frac{\sigma_{y}}{\sigma_{e q, \text { max }, I I}}=\frac{625}{319.4}=1.96
\end{aligned}
$$

- The fatigue analysis showed that the stress value at point 1 exceeded the fatigue boundary line and that fatigue failure safety was not provided.

\subsection{Experimental Testing}

In the second stage, testing was performed at points shown in Fig. 12, to determine mechanical properties presented in Tab. 2, and chemical composition of material, presented in Tab. 3, as well as visual and metallographic examination of shaft fracture surface. The obtained results for the chemical composition and the mechanical properties are within the limits prescribed by the standard (DIN EN 10083) for steel 42CrMo4 [22].

Table 3 Chemical composition of samples and as defined by standard

\begin{tabular}{|c|c|c|c|c|c|c|c|c|}
\hline \multicolumn{2}{|c|}{ Elements (\%) } & $\mathrm{C}$ & $\mathrm{Si}$ & $\mathrm{Mn}$ & $\mathrm{Mo}$ & $\mathrm{Cr}$ & $\mathrm{S}$ & $\mathrm{P}$ \\
\hline $\begin{array}{c}\text { Prescribed } \\
\text { values for } \\
\text { 42CrMo4 } \\
\text { DIN EN 10083 }\end{array}$ & from & 0.38 & $\max$ & 0.6 & 0.15 & 0.9 & $\max$ & $\max$ \\
\cline { 2 - 9 } & 0.45 & 0.4 & 0.9 & 0.30 & 1.2 & 0.035 & 0.025 \\
\hline $\begin{array}{c}\text { Values obtained by } \\
\text { testing }\end{array}$ & 0.44 & 0.29 & 0.67 & 0.16 & 0.99 & 0.021 & 0.017 \\
\hline
\end{tabular}

Values of hardness of material outside the fracture zone, 240-270 HV1, Tab. 4, correspond to the steel $42 \mathrm{CrMo} 4$. Contrary to that, hardness measured at the point of fracture, in both longitudinal and transverse directions, indicates considerable scattering, particularly in the zone of fatigue failure (Fig. 12). The increase in hardness ranges within 347-420 HV1 (Tab. 4).

The values of tensile strength in the critical section can be obtained from the comparative tables for hardness and tensile strength, using the data from Tab. 4 [23]. The comparative table was used because it was not possible to make test pieces necessary for testing of mechanical properties of material in the area of fatigue failure.

\begin{tabular}{|c|c|c|c|c|c|c|c|c|c|c|}
\hline \multirow{2}{*}{\multicolumn{2}{|c|}{$\begin{array}{l}\text { Shaft material 42CrMo4 } \\
\text { (DIN EN 10083) }\end{array}$}} & \multicolumn{9}{|c|}{ Sample label (Fig. 12) } \\
\hline & & 29 & 30 & 25 & 22 & 18 & 20 & 10 & 4 & 3 \\
\hline \multirow{2}{*}{ Measured hardness } & \multirow{2}{*}{ HV1 } & 305 & 310 & 340 & 320 & 280 & 260 & 280 & 282 & 242 \\
\hline & & 345 & 347 & 420 & 398 & 395 & 290 & 305 & 294 & 260 \\
\hline \multirow{4}{*}{$\begin{array}{c}\text { Values obtained by } \\
\text { calculation through } \\
\text { hardness }\end{array}$} & \multirow{2}{*}{$R_{\mathrm{m}}(\mathrm{MPa})$} & 1025 & 1040 & 1140 & 1080 & 940 & 870 & 940 & 946 & 808 \\
\hline & & 1155 & 1161 & 1380 & 1314 & 1305 & 970 & 1025 & 986 & 870 \\
\hline & \multirow{2}{*}{$R_{\mathrm{p} 0,2}(\mathrm{MPa})$} & 820 & 832 & 912 & 864 & 752 & 696 & 752 & 757 & 645 \\
\hline & & 924 & 929 & 1104 & 1051 & 1044 & 776 & 820 & 789 & 695 \\
\hline
\end{tabular}

Table 4 Values of hardness and mechanical properties of the shaft material

\subsection{Visual and Metallographic Inspections}

To examine shaft fracture surface, visual inspection of conveyor belt shaft was followed by metallographic examination using the optical microscope Axiovert25, ZEISS.

Shaft fracture initiated at the edge of zone 3, Fig. 12. The microstructure is homogeneous, pearlitic-ferritic, in accordance with the usual structure of the steel $42 \mathrm{CrMo} 4$ and its heat treatment (Fig. 13) [24, 25]. The strip-like microstructure is seen in the longitudinal section of the shaft, being the undesired consequence of plastic deformation during forging of the shaft (Fig. 13).

It is obvious that the normalizing heat treatment of the shaft did not eliminate the strip-like structure, i.e. the heat treatment procedure was insufficient, reducing significantly material resistance to variable loads and creating favourable conditions for fatigue fractures [26]. 


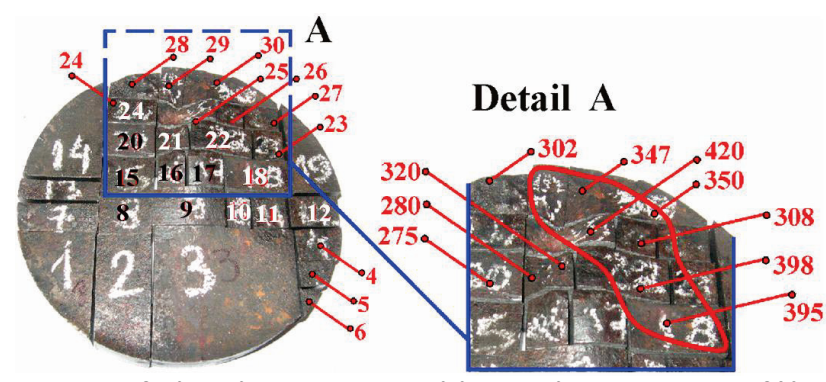

Figure 12 Surface of the drive drum shaft fracture of the conveyor belt TS305 with the points of taking samples for testing
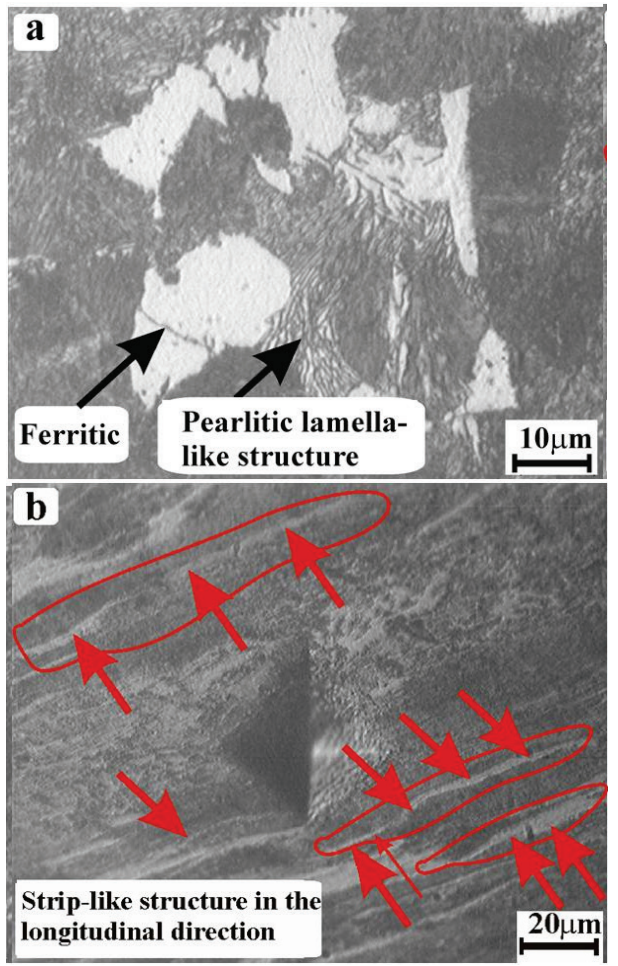

Figure 13 Structure of the drive drum shaft of the conveyor belt TS305: a) ferritic pearlitic structure b) distinct strip-like structure in the longitudinal direction

\subsection{Discussion of the Testing Results}

Chemical composition and mechanical properties of the samples taken at the point of drive shaft fracture are in accordance with the quality of steel $42 \mathrm{CrMo} 4$ (DIN EN 10083). The appearance of the fracture surface (Fig. 5) indicates fatigue fracture with characteristic marks of tearing $[27,28]$, although initiation spot is not clearly seen (Zone 3 - Fig. 12). The most probable reason that fatigue fracture initiation is not clearly seen is the fact that the initial crack is consequence of unfavourable material microstructure. Anyhow, there was no initial crack in material itself.

\section{CONCLUSIONS}

Taking into account presented results, the following conclusions can be made:

- Fracture of the drive shaft of conveyor belt occurred due to superposition of three effects: fatigue loading, stress concentration, and inadequate heat treatment.

- Appearance of fracture surface indicates that the normalizing heat treatment produced unfavourable ferritic-pearlitic microstructure, with strip-like bands, contributing significantly to the failure.

\section{Acknowledgements}

A part of this work is done in the scope of Project TR35038, financed by Ministry of Education, Science and Technological Development of Serbia

\section{REFERENCES}

[1] Timtner, K. (1999). Peak torque calculations for backstops in conveyors. International Mining and Minerals, 15, 81-89. http://www.ringspann.com/files_db/1335332857_85_14.p df

[2] Zimroz, R. \& Krol, R. (2009). Failure analysis of belt conveyor systems for condition monitoring purposes. Scientific Papers of the Institute of Mining University of Technology (Prace Naukowe Instytutu Górnictwa Politechniki Wrocławskiej), 128, 255-270.

[3] CEMA. (2007). Belt conveyors for bulk materials. Florida, USA.

[4] Afolter, Ch., Piskoty, G., Koller, R., Zgraggen, M., \& Ruütti T. F. (2007). Fatigue in the shell of a conveyor drum. Engineering Failure Analysis, 14, 1038-1052. https://doi.org/10.1016/j.engfailanal.2006.11.071

[5] Lihua Zhao \& Yin Lin. (2011). Typical failure analysis and processing of belt conveyor. Procedia Engineering, 26, 942946. https://doi.org/10.1016/j.proeng.2011.11.2260

[6] Babakr, A., Bradley, R., \& Al-Ahmari, A. (2009). Failure Analysis of Mill Shaft Roll. Journal of Failure Analysis and Prevention, 9, 107-113. https://doi.org/10.1007/s11668-009-9215-4

[7] Martínez-Casas, J., Mazzola, L., Baeza, L., \& Bruni, S. (2013). Numerical estimation of stresses in railway axles using a train-track interaction model. International Journal of Fatigue, 47, 18-30. https://doi.org/10.1016/j.jfatigue.2012.07.006

[8] Savković, M., Gašić, M., Arsić, M., \& Petrović, R. (2011). Analysis of the axle fracture of the bucket wheel excavator. Engineering Failure Analysis, 18, 433-441. https://doi.org/10.1016/j.engfailanal.2010.09.031

[9] (1960). Design fundamentals of large-scale equipment in open pit mine (Berechnungsgrundlagen für Großgeräte in Tagebauen). Düsseldorf: Der Minister für Wirtschaft und Verkehr des Landes Nordhein-Wesstfalen.

[10] Arsić, M., Veljovć, A., Rakin, M., \& Radaković, Z. (2008)). Possibility of life assessing the speed reducer for belt conveyor drive by applying tensometric measurements. Structural Integrity and Life, 8(3), 159-164.

[11] Rusinski, E., Czmochowski, J., \& Moczko, P. (2009). Halfshaft undercarriage systems-designing and operating problems. Journal of Achievements in Materials and Manufacturing Engineering, 33(1), 62-69.

[12] Rusinski, E., Harnatkiewicz, P., Bobyr, B., \& Yakhno, B. (2008). Caterpillar drive shaft damage causes analysis. Archives of Civil and Mechanical Engineering, VIII(3), 117129. https://doi.org/10.1016/S1644-9665(12)60167-8

[13] Smith, J. O. (1942). The effect of range of stress on the fatigue strength of metals. Univ. of Ill, Eng. Exp. Sta. Bull., 334.

[14] Shigley, J. E. \& Mitchell, L. D. (1983). Mechanical Engineering Design. $4^{\text {th }}$ ed. New York: McGraw-Hill, 293.

[15] Jubvinall, R. C. (1967). Engineering considerations of stress, strain and strength. New York: McGraw-Hill.

[16] Pyttel, B., Schwerdt, D., Brunner, I., \& Berger, C. (2011). Fatigue strength and failure mechanisms in the VHCFregion. Anales de Mecanica de la Fractura, 28(1), 1-8. 
[17] Pyttel, B., Schwerdt, D., \& Berger, C. (2010). Fatigue strength and failure mechanisms in the VHCF-region for quenched and tempered steel $42 \mathrm{CrMoS} 4$ and consequences to fatigue design. Procedia Engineering, (2), 1327-1336. https://doi.org/10.1016/j.proeng.2010.03.144

[18] Guagliano, M. (2011). Perspectives and problems in shot peening, a mechanical treatment to improve the fatigue behavior of structural parts. Anales de Mecanica de la Fractura, 28(1), 9-19.

[19] Koehler, H., Schumacher, J., Schuischel, K., Partes, K., Bomas, H., Jablonski, F., Vollertsen, F., \& Kienzler, R. (2012). An approach to calculate fatigue properties of laser cladded components. Prod. Eng. Res. Devel., 6, 137-148. https://doi.org/10.1007/s11740-012-0369-7

[20] Marines-Garcia, I., Galvan-Montiel, D., \& Bathias, C. (2008). Fatigue life assessment of high-strength, low alloy steel at high frequency. The Arabian Journal for Science and Engineering, 33(1B), 237-247.

[21] Ferreira, J. A. M., Costa, J. D. M., \& Lapat, V. (1997). Fatigue behaviour of $42 \mathrm{Cr} \mathrm{Mo} 4$ steel with PVD coatings. Int. J. Fatigue, 19(4), 293-299. https://doi.org/10.1016/S0142-1123(97)00007-8

[22] DIN 17200/E DIN EN 10083, 1-3:2006-10. Vergütungsstähle - Teil 3: Technische Lieferbedingüngen für legierte stähle; Deutsche norm, 2007.

[23] Basan, R., Kunc, R., \& Franulović, M. (2008). Monotonic behaviour of normalised and quenched and tempered steel 42CrMo4. Eng. Rev., 28(2), 23-30.

[24] (2004). Metallography and Microstructures. ASM handbook, vol. 9. ASM International.

[25] Šman, H. (1989). Metallography. Belgrade: The Faculty of Technology and Metallurgy. (in Serbian)

[26] Rusinski, E., Harnatkiewicz, P., Kowalczyk, M., \& Moczko, P. (2010). Examination of the causes of a bucket wheel fracture in a bucket wheel excavator. Engineering Failure Analysis, 17, 1300-1312. https://doi.org/10.1016/j.engfailanal.2010.03.004

[27] (2002). Failure analysis and prevention. ASM handbook, vol. 11. Metalspark Ohio: ASM International.

[28] Brooks, R. C. (1993). Metallurgical failure analysis. New York: McGraw-Hill.

\section{Contact information:}

\section{Mile SAVKOVIĆ}

(Corresponding author)

University of Kragujevac,

Faculty of Mechanical Engineering Kraljevo,

Dositejeva 19, 36000 Kraljevo, Serbia

E-mail: savkovic.m@mfkv.kg.ac.rs

\section{Milan DEDIĆ}

University of Kragujevac,

Faculty of Mechanical Engineering Kraljevo,

Dositejeva 19, 36000 Kraljevo, Serbia

E-mail: dedic.m@ mfkv.kg.ac.rs

\section{Goran PAVLOVIĆ}

R\&D Center Alfatec Ltd

Bul. Nikole Tesle 63/5, 18000 Niš, Serbia

\section{Miodrag ARSIĆ}

Institute for Materials Testing IMS, Belgrade

Bulevar vojvode Mišića 43, 11000 Belgrade, Serbia

E-mail: miodrag.arsic@institutims.rs

\section{Zoran STAMENIĆ}

University of Belgrade,

Faculty of Mechanical Engineering

Kraljice Marije 16, 11120 Belgrade 35, Serbia

E-mail: zstamenic@mas.bg.ac.rs 